\title{
Towards Effective Multidisciplinary Engineering Education: The Multidisciplinary Design Stream at Queen's University - Part II
}

\author{
David S. Strong ${ }^{1}$
}

Professional engineers not only have to work frequently with those from other disciplines and professions, but often have to develop working skills and knowledge beyond their original discipline due to the requirements of their employment. Engineering accreditation bodies have accordingly begun to include the ability to function in multidisciplinary teams as a demonstrable requirement for accreditation of engineering schools.

Similarly, engineering design skills are also important attributes for professional engineers, particularly those working in product, process or system development. Although long required by many engineering accreditation bodies, it is perceived by industry that most engineering graduates, although technically competent, have minimal practical design skills.

There are many factors in most Canadian engineering schools that may limit student's development of multidisciplinary and design skills. These include separate engineering departments, departmental funding policies, schedules based on individual disciplines, and heavy core course loads based on the perceived need for more math, science and computer courses. As a result, practical design experiences may be limited to one final year, discipline specific course.

In an effort to address the need for both multidisciplinary and design engineering skills, a Multidisciplinary Design Stream has been developed at Queen's University. Beginning with a course designed to develop a broad range of fundamental engineering design knowledge, skills and attitudes, the stream culminates with a full academic year experience working on industry based design projects in multidisciplinary teams. The first paper in this series, presented at the 2005 CDEN conference, discussed the first course in this stream and laid out the plans for the successive multidisciplinary industrybased design project. This paper will extend that discussion to review the industry project phase and reflect on the overall results of the first full offering of the multidisciplinary design stream.

1. Professor and NSERC Chair in Design Engineering, Faculty of Applied Science - Integrated Learning Centre, Queen's University

Kingston, Ontario K7L 3N6 strongd@post.queensu.ca 